\title{
A Retrospective Observational Study of Dicentric (9;12): A Unique, Nonrandom Translocation Defining a Cytogenetic Subgroup with Favorable Outcome in Acute Lymphoblastic Leukemia
}

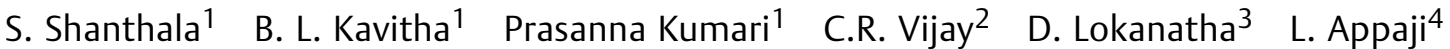 \\ Govind Babu ${ }^{3}$ C. S. Premalata ${ }^{5}$ C. Ramachandra ${ }^{6}$
}

${ }^{1}$ Cytogenetics Unit-Department of Pathology, Kidwai Memorial Institute of Oncology, Bengaluru, Karnataka, India

2 Department of Biostatistics, Kidwai Memorial Institute of Oncology, Bengaluru, Karnataka, India

${ }^{3}$ Department of Medical Oncology, Kidwai Memorial Institute of

Oncology, Bengaluru, Karnataka, India

${ }^{4}$ Department of Pediatric Oncology, Kidwai Memorial Institute of

Oncology, Bengaluru, Karnataka, India

${ }^{5}$ Department of Pathology, Kidwai Memorial Institute of Oncology,

Bengaluru, Karnataka, India

${ }^{6}$ Kidwai Memorial Institute of Oncology, Bengaluru, Karnataka, India

\begin{abstract}
Address for correspondence S. Shanthala, MD, \#789, 9th A Main, Indiranagar 1st Stage, Bangalore, Karnataka, 560038, India (e-mail: drshanthalas@gmail.com).
\end{abstract}

Ind J Med Paediatr Oncol 2022;43:349-354.

\begin{abstract}
\section{Keywords}

- dicentric $(9 ; 12)$

- precursor B cell acute lymphoblastic leukemia

Introduction Cytogenetic abnormalities are integral to the risk stratification of acute lymphoblastic leukemia (ALL).

Objectives The present study aimed to highlight a rare, yet nonrandom cytogenetic abnormality notably dicentric $(9 ; 12)$, which was observed in ALL patients who presented to our institute. The study analyzed the frequency, clinicohematological features, and treatment response of these patients.

Materials and Methods A single-group observational study was conducted from April 2014 to April 2020. Cytogenetic analysis was done on bone marrow aspirate samples of the patients referred to the cytogenetics laboratory with clinical diagnosis of acute leukemia. Cytogenetic, clinical, and hematological data were collected from respective departmental records, case files, and patients.

Results $\operatorname{Dic}(9 ; 12)$ was identified in $1.2 \%$ of ALL (19 out of 1,544 patients). They showed striking preponderance in teen and young adult males with characteristic precursor $B$ cell immunophenotype. Majority of these patients displayed favorable risk profiles such as low total count, mild lymphadenopathy and splenomegaly, mild-to-moderate elevation of lactate dehydrogenase, and good response to first induction chemotherapy. Rare coexistence of dic $(9 ; 12)$ with well-established cytogenetic markers such as $t(9 ; 22)$ and $t(1 ; 19)$ was observed. Conclusion $\operatorname{Dic}(9 ; 12)$ is one of the most specific cytogenetic markers of precursor $B$ cell (pre-B) ALL. It defines a subgroup with favorable clinical and biological profile. We
\end{abstract}

DOI https://doi.org/ 10.1055/s-0041-1732859. ISSN 0971-5851. (c) 2021. Indian Society of Medical and Paediatric Oncology. All rights reserved.

This is an open access article published by Thieme under the terms of the Creative Commons Attribution-NonDerivative-NonCommercial-License, permitting copying and reproduction so long as the original work is given appropriate credit. Contents may not be used for commercial purposes, or adapted, remixed, transformed or built upon. (https://creativecommons.org/ licenses/by-nc-nd/4.0/)

Thieme Medical and Scientific Publishers Pvt. Ltd., A-12, 2nd Floor, Sector 2, Noida-201301 UP, India 
suggest inclusion of $\operatorname{dic}(9 ; 12)$ in cytogenetic risk stratification of precursor B cell ALL. Long-term follow-up studies are recommended to establish the prognostic significance of this cytogenetic subgroup, which may benefit from less intensive chemotherapy.

\section{Introduction}

The World Health Organization (WHO) classification of B cell acute lymphoblastic leukemia (ALL)/lymphoma (2017) is refined by risk stratification model based on the recurrent chromosomal abnormalities. High hyperdiploidy, $t(12 ; 21)$, $t$ $(1 ; 19)$, and $\mathrm{t}(9 ; 22)$ are most commonly considered cytogenetic abnormalities in prognostication. ${ }^{1}$

Only 110 cases of dicentric $(9 ; 12)$ have been reported to date since its first discovery in 1985 by Faderl et al, ${ }^{2}$ although it was Carroll et al in 1987, who recognized this abnormality as a recurrent finding in childhood ALL. ${ }^{3}$ There has been no update until the last couple of years on this unique translocation, which is possibly associated with good prognosis. With this background, the present study aims to assess the overall frequency of $\operatorname{dic}(9 ; 12)$ in ALL and comprehensively analyze the associated clinicohematological features.

\section{Materials and Methods}

This was a single-group retrospective observational study conducted from April 2014 to April 2020. Nineteen patients having $\operatorname{dic}(9 ; 12)$ were retrieved from the cytogenetic records. Patients of ALL were identified based on the information obtained from cytogenetic registers (from 2014 to 2020) and departmental records of medical and pediatric oncology. Clinical and hematological parameters were obtained from the case files.

\section{Cytogenetic Technique}

Heparinized bone marrow aspirates of the patients were sent to the cytogenetics laboratory. Dual cultures of 24-hour and 48-hour incubation were set up in RPMI-1640 medium supplemented with $15 \%$ qualified, heat-inactivated fetal bovine serum (GIBCO, Invitrogen, United States). This was followed by mitotic arrest using Karyomax-Colcemid solution $(0.10 \mu \mathrm{g} / \mathrm{mL}$ concentration $)$ for 30 minutes. Subsequently, cells were subjected to hypotonic treatment in potassium chloride $(0.075 \mathrm{M})$ at $37^{\circ} \mathrm{C}$ for 20 minutes and overnight fixation in Carnoy's fixative solution (3:1 concentration of methanol and glacial acetic acid). Giemsa-Trypsin-Giemsa banding was done on prepared slides, and chromosomal analysis was done in accordance with the International System for Chromosomal Nomenclature. Good quality metaphases were captured and analyzed using Olympus applied spectral imaging software version 8.1.0.47741.

\section{Statistical Methods}

Python 3.7 software was used for statistical analysis. Descriptive statistical analysis (frequencies, mean, median, and range) was done to analyze baseline parameters. Fisher's exact test was applied to find the association between complex karyotype and risk stratification. Survival probabilities were estimated by Kaplan-Meier method.

\section{Ethics}

The procedures were in accordance with the ethical standards of the responsible committee on human experimentation (institutional) and with the Helsinki Declaration of 1964, as revised in 2013. Ethics Committee Waiver was obtained from Kidwai Memorial Institute of Oncology (dated 1204-2020, KMIO/DPT/106/2021). The informed consent was waivered due to the retrospective nature of the study.

\section{Results}

Nineteen patients of $\operatorname{dic}(9 ; 12)$ were identified among 1544 patients of ALL and 1214 patients of B cell ALL, accounting for frequencies of 1.2 and $1.6 \%$, respectively.

The median age of patients was 14 years (range: $1-57$ years). Majority of patients (12 out of 19 patients; 63\%) were adolescents and young adults (10-23 years). Males were more frequently affected than females $(\mathrm{M}: \mathrm{F}=4: 1)$. Clinical features and hematologic and biochemical parameters are summarized in - Tables $\mathbf{1}$ and $\mathbf{2}$, respectively.

Bone marrow examination revealed blasts having L1/L2 morphology of French-American-British classification. Normal bone marrow elements were suppressed. Immunophenotypically, the blasts were positive for Tdt, CD34, CD10, CD19, CCD79a, and human leukocyte antigen-DR and negative for T cell and myeloid markers. CD20-positive expression was noted in only six cases. Features were consistent with the diagnosis of precursor B cell ALL.

\section{Cytogenetic Studies}

Hypodiploidy (modal number of chromosomes ranging from 44 to 45 ) was observed in 16 out of 19 patients (84\%) (-Table 3). Patients with 45 chromosomes were considered

Table 1 Clinical features of patients with $\operatorname{dic}(9 ; 12)$ at diagnosis

\begin{tabular}{|l|l|}
\hline Signs and symptoms & Percentage of patients \\
\hline Fever and fatigue & $73-80$ \\
\hline $\begin{array}{l}\text { Others: cough, } \\
\text { neck swelling, epistaxis }\end{array}$ & 6 \\
\hline Moderate pallor & 21 \\
\hline Severe pallor & 79 \\
\hline Lymphadenopathy & 87 \\
\hline Hepatomegaly & 64 \\
\hline Splenomegaly & 76 \\
\hline
\end{tabular}

Abbreviation: $\operatorname{dic}(9 ; 12)$, dicentric $(9 ; 12)$. 
Table 2 Clinical, biochemical, and hematological parameters of patients with $\operatorname{dic}(9 ; 12)$ at diagnosis

\begin{tabular}{|l|l|l|}
\hline Parameters & Median & Range \\
\hline Liver size on ultrasound & $17 \mathrm{~cm}$ & $13-20 \mathrm{~cm}$ \\
\hline Spleen size on ultrasound & $15.5 \mathrm{~cm}$ & $10-20 \mathrm{~cm}$ \\
\hline $\mathrm{LDH}$ & 347 & $205-552$ \\
\hline $\mathrm{Hb}(\mathrm{g} / \mathrm{dl})$ & 8 & $4-11$ \\
\hline $\mathrm{TC}\left(n \times 10^{9} / \mathrm{L}\right)$ & 3 & $1-113$ \\
\hline ANC $\left(n \times 10^{9} / \mathrm{L}\right)$ & 0.45 & $0.02-15.36$ \\
\hline Platelets $\left(n \times 10^{9} / \mathrm{L}\right)$ & 25.5 & $2-71$ \\
\hline PBL blast $(\%)$ & 40 & $22-70$ \\
\hline BM blast $(\%)$ & 80 & $50-90$ \\
\hline
\end{tabular}

Abbreviations: ANC, absolute neutrophil count; BM, bone marrow; dic $(9 ; 12)$, dicentric $(9 ; 12)$; Hb, hemoglobin; $\mathrm{LDH}$, lactate dehydrogenase; $\mathrm{PBL}$, peripheral blood; TC, total count.

near-diploid since it occurred as a result of unbalanced translocation $\operatorname{dic}(9 ; 12)$. - Fig. 1 represents the novel translocation $\operatorname{dic}(9 ; 12)$. Complex karyotype is defined as metaphases having at least three chromosomal abnormalities, irrespective of their type. As per these criteria, 7 out of 19 patients (37\%) in our study group had complex karyotype. The additional structural abnormalities observed in our study group included $t(9 ; 22), t(1 ; 19)$, del $(9 p)$, del(7q), marker chromosomes, and numerical abnormalities. -Fig. 2
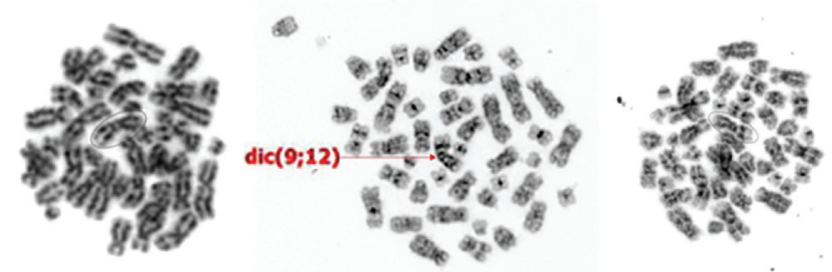

Fig. 1 Metaphases of $\operatorname{dic}(9 ; 12)$ abnormality identified in different patients.

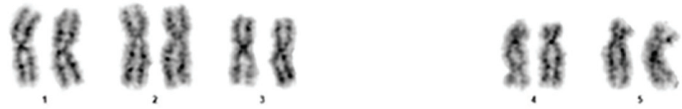

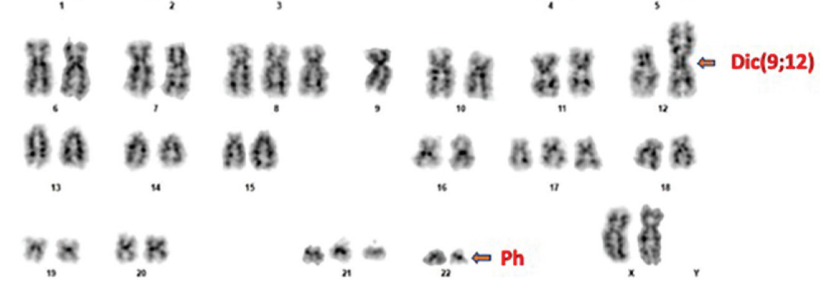

Fig. 2 Karyotype: 48,XX,+8, $\operatorname{dic}(9 ; 12)(\mathrm{p} 13 ; \mathrm{p} 13),+17,+21, \operatorname{der}(22) \mathrm{t}$ $(9 ; 22)$ (q34;q11.2). dic $(9 ; 12)$; dicentric dic $(9 ; 12)$.

denotes coincidence of $\operatorname{dic}(9 ; 12)$ and Philadelphia chromosome along with numerical abnormalities in a single metaphase. Although derivative chromosome 9 appeared cryptic in the metaphase, fluorescent in situ hybridization confirmed $b c r$-abl translocation (-Fig. 3). Reverse transcriptase

Table 3 Cytogenetic findings of patients with $\operatorname{dic}(9 ; 12)$ at diagnosis

\begin{tabular}{|c|c|c|c|}
\hline Case number & Age $(\mathrm{y}) /$ gender & Karyotype & Complex karyotype \\
\hline 1 & $6 /$ male & 45,XY,dic(9;12)(p11;p11-12)[8]/46,XY[4] & No \\
\hline 2 & 10/female & 48,XX,+8,dic(9;12)(p23;q13),del(9)(p21),+2mar & Yes \\
\hline 3 & $12 / \mathrm{male}$ & $45, \mathrm{XY}, \operatorname{dic}(9 ; 12)(\mathrm{p} 11 ; \mathrm{p} 12)$ & No \\
\hline 4 & 13/male & 45,XY,del(7)(q31),dic(9;12)(p13;p13) & Yes \\
\hline 5 & $14 / \mathrm{male}$ & $45, \mathrm{XY}, \operatorname{dic}(9 ; 12)(\mathrm{p} 11-13 ; \mathrm{p} 11)$ & No \\
\hline 6 & $14 /$ male & $45, \mathrm{XY}, \operatorname{dic}(9 ; 12)(\mathrm{p} 11 ; \mathrm{p} 11), \mathrm{t}(1 ; 19)(\mathrm{q} 23 ; \mathrm{p} 13)$ & Yes \\
\hline 7 & 15/male & $45, \mathrm{XY}, \operatorname{dic}(9 ; 12)(\mathrm{p} 13 ; \mathrm{p} 13)$ & No \\
\hline 8 & 15/female & 44,XX,dic(9;12)(p13;p13),-17 & No \\
\hline 9 & $17 / \mathrm{male}$ & 45,XY,dic(9;12)(p13;p13) & No \\
\hline 10 & $21 / \mathrm{male}$ & $45, \mathrm{XY}, \operatorname{dic}(9 ; 12)(\mathrm{p} 13 ; \mathrm{p} 13)$ & No \\
\hline 11 & $23 / \mathrm{male}$ & 45,XY,der(9)t(9;12)(p13;p13)t(9;22)(q34;q11.2) & Yes \\
\hline 12 & 20/male & 44,X,-Y,dic(9;12)(p13;p13) & No \\
\hline 13 & 43/female & 45,XX,dic(9;12)(p13;p13) & No \\
\hline 14 & $01 /$ male & $45, \mathrm{XY}, \operatorname{dic}(9 ; 12)(\mathrm{p} 11-12 ; \mathrm{p} 13)$ & No \\
\hline 15 & $57 /$ male & $45, \mathrm{XY},-2, \mathrm{i}(8)(\mathrm{q} 10), \operatorname{dic}(9 ; 12)(\mathrm{p} 11 ; \mathrm{p} 11), \mathrm{t}(9 ; 22)(\mathrm{q} 34 ; \mathrm{q} 11.2)$ & Yes \\
\hline 16 & 19/female & 46,XX,dic(9;12)(p13;p13),-10,+2mar & Yes \\
\hline 17 & 11/female & 46,XX,dic(9;12)(p13;q13),t(9;22)(q34;q11.2) & Yes \\
\hline 18 & $8 /$ male & 45,XY,dic(9;12)(p13;p13) & No \\
\hline 19 & 9/male & 45,XY,dic(9;12)(p13;p13) & No \\
\hline
\end{tabular}

Abbreviation: $\operatorname{dic}(9 ; 12)$, dicentric $(9 ; 12)$. 


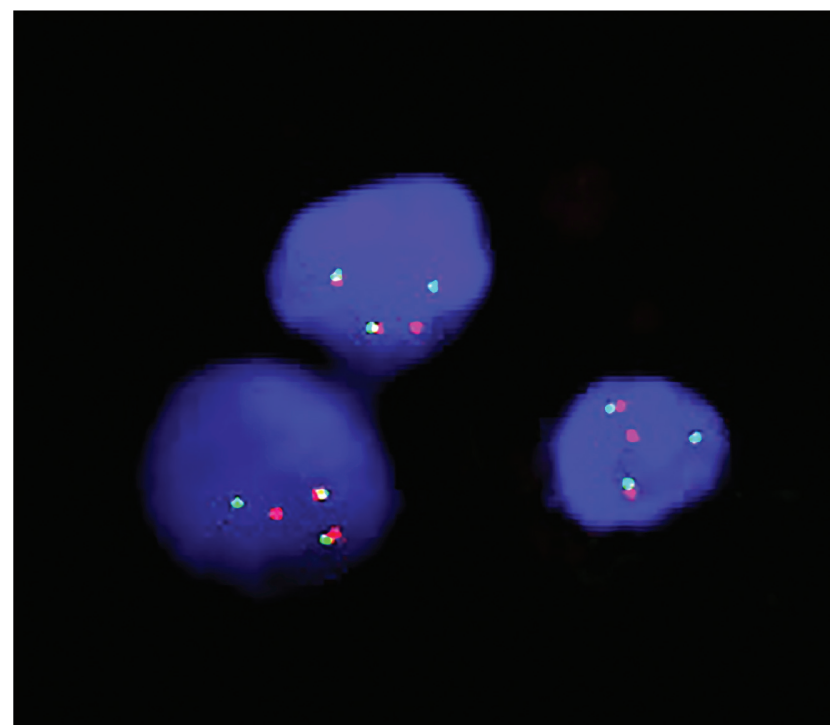

Fig. 3 Fluorescent in situ hybridization (dual color, dual fusion): Two red-green, one green, and one red signals confirm bcr-abl translocation.

polymerase chain reaction showed major $b c r-a b l$ transcripts in three patients harboring $\mathrm{t}(9 ; 22)$.

\section{Treatment and Follow-Up}

Pediatric patients were treated according to the MCP-841 chemotherapeutic regimen until 2018 and Indian Childhood
Collaborative Leukemia Group ALL-14 protocol since 2019. Adult patients were given chemotherapy according to BFM95 ALL regimen. A 23-year-old male of Ph-positive ALL with $\operatorname{dic}(9 ; 12)$ received $\mathrm{R}$-Hyper-CVAD protocol along with imatinib. Majority of patients belonged to standard and intermediate-risk group (81\%; 13 out of 16 patients) (-Table 4 ). All patients achieved complete hematologic and cytogenetic remission within 4 to 6 weeks of first induction chemotherapy. Minimal residual disease status was evaluated for six pediatric patients, who showed leukemic cell count $<0.01 \%$ in the bone marrow.

Out of 19 patients, 10 were selected for survival analysis because other nine patients had still not completed treatment. The median duration of follow-up was 36 months (range: 7-51 months) (-Table 4). The overall survival was estimated to be $67 \%$ for 3 years. The survival curve is depicted in -Fig. 4. A 15-year-old girl died of disease following discontinuation of treatment for 19 months. Deaths of a 43-year-old female and a 57-year-old male were attributed to their comorbid conditions.

\section{Discussion}

A dicentric chromosome is a single chromosome that has two centromeres, causing genomic instability and evolution of the disease in cancer. ${ }^{4}$ There is considerable heterogeneity in breakpoints and the fusion gene partners in dicentric chromosomal rearrangements involving chromosome $9 \mathrm{p} .{ }^{5}$ Despite the

Table 4 Risk stratification, duration of follow-up, and survival status of patients with dic(9;12)

\begin{tabular}{|l|l|l|l|}
\hline Case number & Risk stratification & Duration of follow-up in months & Survival status \\
\hline 1 & Standard & 36 & Remission \\
\hline 2 & Standard & 51 & Remission \\
\hline 3 & Standard & 7 & On treatment \\
\hline 4 & Standard & 6 & On treatment \\
\hline 5 & Standard & 37 & Lost follow-up \\
\hline 6 & Not available & 36 & Remission \\
\hline 7 & Standard & 40 & Remission \\
\hline 8 & High & 19 & Dead \\
\hline 9 & Intermediate & 12 & On treatment \\
\hline 10 & Intermediate & 16 & Lost follow-up \\
\hline 11 & High & 36 & Remission \\
\hline 12 & Intermediate & 9 & On treatment \\
\hline 13 & Intermediate & 7 & Dead \\
\hline 14 & Not available & 9 & On treatment \\
\hline 15 & High & 28 & Dead \\
\hline 16 & Intermediate & 9 & On treatment \\
\hline 17 & Intermediate & 8 & On treatment \\
\hline 18 & Not available & 2 & On treatment \\
\hline 19 & Standard & 2 & On treatment \\
\hline
\end{tabular}

Abbreviation: $\operatorname{dic}(9 ; 12)$, dicentric $(9 ; 12)$. 


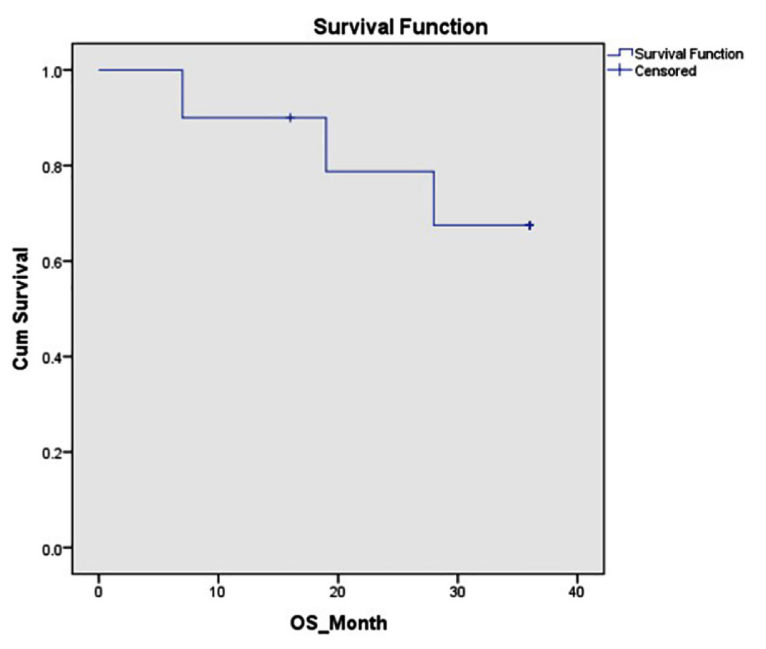

Fig. 4 Survival outcome analysis of patients with $\operatorname{dic}(9 ; 12)$ by Kaplan-Meier method. dic $(9 ; 12)$; dicentric dic $(9 ; 12)$.

heterogeneity, molecular investigations have shown 9p rearrangements including deletion or gene fusions resulted in partial or complete deletion and under expression of PAX5 gene. ${ }^{5}$ The usual partner chromosomes are 7,12 , and $20 .{ }^{6}$

$\operatorname{Dic}(9 ; 12)(\mathrm{p} 11-13 ; \mathrm{p} 11-13)$ is an unbalanced translocation with partial loss of short arms of chromosomes 9 and 12 . This results in fusion of PAX5 gene on short arm of chromosome 9 with ETV6 gene on short arm of chromosome 12, resulting in PAX5-ETV6 chimeric fusion protein.

Similar to earlier studies on $\operatorname{dic}(9 ; 12),{ }^{7-9}$ the peak incidence was noted in teenage and young adult males in the present study. This translocation is rarely encountered in infants and the elderly. Only a single case of a 66-year-old woman with $\operatorname{dic}(9 ; 12)$ in pre-B-ALL has been reported so far. ${ }^{9}$ Two patients in our study group were older adults (aged 43 and 57 years).

Marked elevation of lactate dehydrogenase (LDH) serves as a surrogate for high leukemic blasts. ${ }^{10}$ The present study showed marginal-to-moderate elevation of LDH and median blast of $40 \%$ (-Table 2). Dicentric translocations are seemingly most prevalent in leukemias of $B$ cell lineage. ${ }^{11} \operatorname{Dic}(9 ; 12)$ is predominantly a marker of precursor B cell ALL, though there are anecdotal reports of this abnormality in chronic myeloge- nous leukemia (CML)-blast crisis and T cell lymphoid malignancies. ${ }^{3,8,9}$ All 19 patients in our study were diagnosed as precursor B cell ALL.

UKCCG 1992 reported better prognosis in patients with $\operatorname{dic}(9 ; 12)$ than in patients with other translocations involving $9 p$ and $12 p$. Patients with $\operatorname{dic}(9 ; 12)$ possibly achieve complete remission with a 5-year survival rate of more than 95\%, abrogating the need for bone marrow transplantation. $^{12,13}$

Mahmoud et al identified 15 cases of $\operatorname{dic}(9 ; 12)$ supposed to be $\operatorname{dic}(9 ; 12)(\mathrm{p} 11 ; \mathrm{p} 12)$ in their study of 2,303 pediatric ALL patients. On median follow-up of 57 months, all were in remission. ${ }^{8}$ Behrendt et al reported 31 cases of leukemia with $\operatorname{dic}(9 ; 12)(\mathrm{p} 11-13 ; \mathrm{p} 11-12)$. Fourteen patients had preB-ALL with clinical and hematologic profile similar to our study group. Despite the presence of one or more adverse prognostic factors, $94 \%$ of these patients remained in remission on 5-year follow-up. ${ }^{9}$ Illade et al reported a 14 -year-old male with $\mathrm{t}(9 ; 12)(\mathrm{p} 13 ; \mathrm{p} 13)$, who was in remission on 4 -year follow-up. ${ }^{14}$ In concordance with these studies, we observed overall survival of $67 \%$ for 3 years ( - Fig. 4). Considering the death of two patients not directly related to the disease, the 3 -year overall survival could be deduced as $90 \%$ in our study.

In general, low hypodiploidy having chromosomes $<40$ and complex karyotype is considered to be independent poor prognostic factors in ALL. ${ }^{15,16}$ Majority of cases in our study were near-diploid or diploid, which is not considered as a poor prognostic factor. The relationship between presence or absence of complex karyotype and risk stratification was not statistically significant (Fisher's exact test, $p=$ 0.504 ; - Table 5). However, patients with complex karyotype also showed good initial treatment response.

$\operatorname{Dic}(9 ; 12)$ and $\operatorname{dic}(7 ; 9)$ frequently coexist with $t(12 ; 21)$ (ETV6-RUNX1 fusion) and $\mathrm{t}(9 ; 22)(B C R-A B L 1$ fusion), respectively, which are considered to be important cooperating genetic events. ${ }^{5}$ Bargetzi et al have reported $\operatorname{dic}(9 ; 12)$ involving derivative chromosome 9 of $\mathrm{t}(9 ; 22)$ in patients with CML-blast crisis. ${ }^{17}$

Conversely, three patients in our study showed $\operatorname{dic}(9 ; 12)$ and $t(9 ; 22)$ as coexisting abnormalities ( - Fig. 3 ) and all were diagnosed as de novo precursor B-ALL. One of these patients who aged 57 years and had comorbid conditions died at 28 months of treatment.

Table 5 Fisher's exact test to find the association between dic(9;12) with or without complex karyotype and risk stratification

\begin{tabular}{|c|c|c|c|c|}
\hline $\begin{array}{l}\text { Risk stratification of patients against presence } \\
\text { and absence of complex karyotype }\end{array}$ & Standard & Intermediate & High & Total \\
\hline $\operatorname{Dic}(9 ; 12)$ with complex karyotype & 2 & 2 & 2 & 6 \\
\hline Percentage within risk stratification & 29 & 33 & 67 & 38 \\
\hline $\operatorname{Dic}(9 ; 12)$ without complex karyotype & 5 & 4 & 1 & 10 \\
\hline Percentage within risk stratification & 71 & 67 & 33 & 63 \\
\hline Total & 7 & 6 & 3 & 16 \\
\hline
\end{tabular}

Abbreviation: $\operatorname{dic}(9 ; 12)$, dicentric $(9 ; 12)$. 


\section{Conclusion}

The current study showed that $\operatorname{dic}(9 ; 12)(\mathrm{p} 13 ; \mathrm{p} 13)$ is a rare, yet recurrent chromosomal abnormality, with an overall frequency of $1.2 \%$ in ALL and 1.6\% in B cell ALL. Based on the findings of this study and review of literature, we believe that patients with this abnormality show standard risk profile with initial good response to induction chemotherapy. Hence, we suggest incorporation of $\operatorname{dic}(9 ; 12)$ in risk stratification of precursor B cell ALL as it represents a group with favorable risk profile and good initial response to treatment. We observed rare concurrence of two nonrandom translocations, $\operatorname{dic}(9 ; 12)$ and $\mathrm{t}(9 ; 22)$. Until the prognostic impact of dic $(9 ; 12)$ is well established by larger studies, it is better to consider $t(9 ; 22)$ over $\operatorname{dic}(9 ; 12)$ in risk stratification of such cases. The current study is limited by small sample size and short duration of follow-up. Survival analysis could be confounded by different treatment protocols used among pediatric and adult patients. Additional studies are being sought to evaluate the prognostic value of this unique cytogenetic aberration, which may benefit from less intense chemotherapy.

\section{Funding}

None.

\section{Conflict of Interest}

None declared.

\section{Acknowledgment}

We would like to express our special gratitude to cytogenetics technical team and departments of medical and pediatric oncology for their cooperation.

\section{References}

1 Borowitz MJM J Borowitz. , Chan JKJ K Chan., Downing JRJ R Downing. , Le Beau MMM M Le Beau. , Arber DAD A Arber. . Blymphoblastic leukaemia/lymphoma with recurrent genetic abnormalities. In: Swerdlow SH, Campo E, Harris NL, Jaffe ES, Pileri SA, Stein H, et al. eds. WHO Classification of Tumors of Haematopoietic and Lymphoid Tissues, Revised. 4th edition. Lyon: International Agency for Research on Cancer; 2017:200-209

2 Faderl S, Kantarjian HM, Talpaz M, Estrov Z. Clinical significance of cytogenetic abnormalities in adult acute lymphoblastic leukemia. Blood 1998;91(11):3995-4019
3 Carroll AJ, Raimondi SC, Williams DL, et al. tdic(9;12): a nonrandom chromosome abnormality in childhood B-cell precursor acute lymphoblastic leukemia: a Pediatric Oncology Group Study. Blood 1987;70(06):1962-1965

4 Mackinnon RN, Campbell LJ. The role of dicentric chromosome formation and secondary centromere deletion in the evolution of myeloid malignancy. Genet Res Int 2011:643628

5 An Q, Wright SL, Konn ZJ, et al. Variable breakpoints target PAX5 in patients with dicentric chromosomes: a model for the basis of unbalanced translocations in cancer. Proc Natl Acad Sci U S A 2008;105(44):17050-17054

6 Smith A, Das P, O'Reilly J, Patsouris C, Campbell LJ. Three adults with acute lymphoblastic leukemia and $\operatorname{dic}(7 ; 9)(\mathrm{p} 11.2 ; \mathrm{p} 11$. Cancer Genet Cytogenet 2006;166(01):86-88

7 United Kingdom Cancer Cytogenetics Group (UKCCG) Translocations involving $9 p$ and/or $12 p$ in acute lymphoblastic leukemia. Genes Chromosomes Cancer 1992;5(03):255-259

8 Mahmoud H, Carroll AJ, Behm F, et al. The non-random dic(9;12) translocation in acute lymphoblastic leukemia is associated with B-progenitor phenotype and an excellent prognosis. Leukemia 1992;6(07):703-707

9 Behrendt H, Charrin C, Gibbons B, et al. Dicentric $(9 ; 12)$ in acute lymphocytic leukemia and other hematological malignancies: report from a dic(9;12) study group. Leukemia 1995;9(01):102-106

10 Md Elbossaty WF. Lactate dehydrogenase (LDH) as prognostic marker in acute leukemia "quantitative method". J Blood Disord Transfus 2017;8:375

11 Raimondi SC, Privitera E, Williams DL, et al. New recurring chromosomal translocations in childhood acute lymphoblastic leukemia. Blood 1991;77(09):2016-2022

12 Huret JL, Heerema NA, Brizard A, et al. Two additional cases of $t$ dic (9:12) in acute lymphocytic leukemia (ALL): prognosis in ALL with $\operatorname{dic}(9: 12$. Leukemia 1990;4(06):423-425

13 Strehl S, König M, Dworzak MN, Kalwak K, Haas OA. PAX5/ETV6 fusion defines cytogenetic entity $\operatorname{dic}(9 ; 12)(\mathrm{p} 13 ; \mathrm{p} 13$. Leukemia 2003;17(06):1121-1123

14 Illade L, Fioravantti V, Andion M, Hernandez-Marques C, Madero L, Lassaletta A. Dicentric translocation $(9 ; 12)$ in acute lymphoblastic leukemia: a chromosomal abnormality with an excellent prognosis? Tumori 2017;103(Suppl 1):e44-e46

15 Woo JS, Alberti MO, Tirado CA. Childhood B-acute lymphoblastic leukemia: a genetic update. Exp Hematol Oncol 2014;3:16

16 Terwilliger T, Abdul-Hay M. Acute lymphoblastic leukemia: a comprehensive review and 2017 update. Blood Cancer J 2017;7 (06):e577

17 Bargetzi MJ, Mühlematter D, Tichelli A, Jotterand M, Wernli M. Dicentric translocation $(9 ; 12)$ presenting as refractory Philadelphia chromosome-positive acute B-cell lymphoblastic leukemia. Cancer Genet Cytogenet 1999;113(01):90-92 